\title{
Effects and influencing factors on hemorheological variables taken into consideration in surgical pathophysiology research
}

\author{
Norbert Nemeth $^{\mathrm{a}, *}$, Adam Deak ${ }^{\mathrm{a}}$, Zsolt Szentkereszty ${ }^{\mathrm{b}}$ and Katalin Peto ${ }^{\mathrm{a}}$ \\ ${ }^{a}$ Department of Operative Techniques and Surgical Research, Institute of Surgery, \\ Faculty of Medicine, University of Debrecen, Debrecen, Hungary \\ ${ }^{\mathrm{b}}$ Institute of Surgery, Faculty of Medicine, University of Debrecen, Debrecen, Hungary
}

\begin{abstract}
In surgical pathophysiology ischemia-reperfusion, inflammatory processes, sepsis, vascular interventions, tissue trauma, shock, all mean conditions in which hemorheological parameters show alterations. Despite of numerous clinical and experimental studies, the in vivo hemorheology is not completely understood yet, and several fundamental questions still need to be answered. Investigating these issues, experimental surgical models are important, in point of view of the translational research as well. In this paper we aimed to make an attempt on summarizing the possible factors and conditions that might have an effect on hemorheological results in experimental surgical studies. Hemorheological parameters show alterations in surgical pathophysiological processes in a complex way. However, the changes are dominantly non-specific. Standardized experimental conditions, related to the experimental animal (species, animal welfare) anesthesia-medications, operation, sampling and, if applicable, conditions of the postoperative period, are inevitable for a safe assessment of valuable (hemorheological) results. Parallel investigations -such as microcirculatory monitoring, imaging techniques, other laboratory methods, histomorphology- have great importance, together with individual analysis of changes, for a better understanding of the changes and for comparability with clinical results.
\end{abstract}

Keywords: Hemorheology, experimental surgery, experimental design, inter-species differences

\section{Introduction}

Since many decades, surgery together with surgical research has been a challenging field of basic, applied and clinical hemorheology. At the dawn of clinical hemorheology a noble Swedish surgeon professor, Lars-Erik Gelin (1920-1980), when investigated anemia of injury, revealed the importance of altered flow properties of blood with postcapillary stagnation of red blood cells and a relative increase in fibrinogen concentration [1]. Their intensive research work led to the development of the Dextran 40 as a therapeutic agent for improving blood flow [1,2]. At that era surgery was a very flourishing field of clinical hemorheology.

In surgical pathophysiology ischemia-reperfusion -as part of necessary interventions in parenchymal organ surgery, operations on extremities, tissue/organ transplantation, presented in compartment syndromes, traumatic vessel occlusions-, inflammatory processes, sepsis, vascular interventions, such

\footnotetext{
*Corresponding author: Norbert Nemeth MD, PhD, DSc, Department of Operative Techniques and Surgical Research, Institute of Surgery, Faculty of Medicine, University of Debrecen, H-4032 Debrecen, Nagyerdei krt. 98., Hungary. Tel./Fax: +36 52416 915; E-mail: nemeth@med.unideb.hu.
} 
as intravascular devices, presence of anastomoses, shunts, tissue trauma, shock, all mean conditions in which hemorheological parameters show alterations [3-7]. The magnitude of changes can be different, though, dominantly being non-specific. At the same time, micro-rheological parameters, such as red blood cell deformability, mechanical stability and aggregation play important roles in determining microvascular flow pattern [8-10]. In the literature there are controversial data on the relation of micro-rheological impairment and microcirculatory deterioration. It is still unknown what the exact magnitude of micro-rheological changes is that will turn to microcirculatory deterioration in a given tissue area, organ or in the whole body.

Despite of numerous clinical and experimental studies, the in vivo hemorheology is not completely understood, yet, and several fundamental questions still need to be answered. Numerous unsolved problems exist related to the time factor, the range of reversibility-irreversibility of local versus systemic hemorheological changes, the relation of altered micro-rheological factors to microcirculatory events during and after surgery. The process of erythrocyte aggregation and its role in pathophysiological processes have not been elucidated completely yet $[11,12]$. Controversial data are available on the basic mechanisms and background of red blood cell mechanical stability and mechanical trauma [5]. Further important concerns are the issues of experimental design: inter-species, age- and gender differences, comparability of the blood sampling sites, and sample handling standardizations, as well as methodological adaptations $[6,13]$.

Investigating these issues, experimental surgical models are still important, in point of view of the translational research as well. In this paper we aimed to make an attempt on summarizing the possible factors and conditions that might have an effect on hemorheological results in experimental surgical studies.

\section{Main factors and pathophysiological processes affecting the rheology of blood}

Any surgical intervention affects the whole body. Among others, anesthesia, immobilization, possible blood loss, volume therapy, the intervention itself, wound healing, postoperative period, metabolism, all have an influence on the condition. Thus, in experimental surgical models the complex approach is essential.

Tissue damage, hypoxia, mechanical trauma to blood, free radicals -deliberated during reperfusion of a previous ischemically insulted tissue and/or by inflammation-alters micro-rheological parameters via different mechanisms (Fig. 1).

Metabolic (decrease in $\mathrm{pH}$, increase of $\mathrm{H}^{+}$and lactate) and micro-environmental osmolarity changes alter the morphological and mechanical properties of blood cells. The $\mathrm{pH}$ decrease turns the red bloods cells' discocyte shape into a stomacyte or sphero-stomacyte form. While, when ATP depletion and calcium accumulation are dominant, the echinocyte and sphero-echinocyte forms appear. Both morphological transformations are associated with deterioration of red blood cells' deformability and disturbed aggregation $[14,15]$. Change in oxygenation is known to alter micro-rheology. Deoxygenated red blood cells have decreased deformability and enhanced aggregation. Under hypoxia, the swelling alters the cellular surface/volume ratio, thus deformability as well [13, 16-18].

Mechanical trauma to blood cells also has to be taken into consideration [5, 19, 20]. In conditions leading to ischemia and reperfusion (e.g., clamping vessels, obturation/occlusion and revascularization) and by usage of various intravascular devices for diagnosis and for therapy (including vascular stents, grafts, prostheses, artificial valves, etc), mechanical trauma to blood appears [5, 7]. For instance, in sepsis, red blood cells can be damaged mechanically due to the presence of thrombi and micro-thrombi (DIC), or even during therapeutic efforts, such as direct removal of toxins from the bloodstream by high-volume hemofiltration as well [5, 21]. 


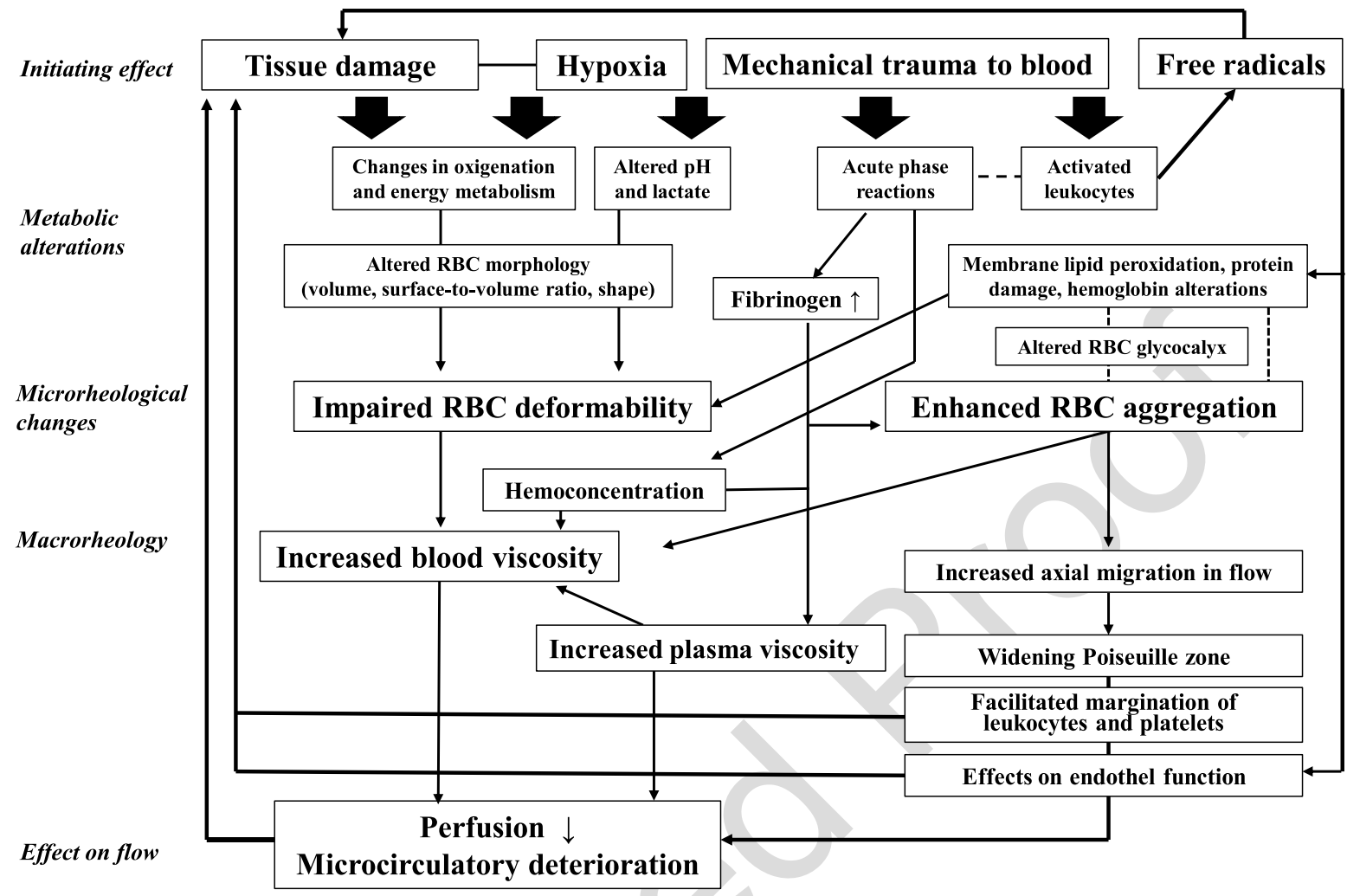

Fig. 1. Schematic summary of factors and effects influencing the fluidity of blood, and their inter-relations. Initiating effects (tissue damage, hypoxia, mechanical trauma to blood, free radicals, and in combinations) lead to metabolic alterations and inflammatory processes affecting micro- and macro-rheological parameters, flow characteristics and endothelial functions, resulting in microcirculatory disturbances and decrease in perfusion. And it generates further tissue damage.

In the circulation blood cells are exposed to mechanical stress during their entire life-span. A shear stress in the range of about 5-20 Pa may even improve the red blood cell deformability in a reversible way, by NO release from the cells [22-24]. Higher shear stress, depending on the magnitude and exposure time, causes mechanical trauma to the blood cells [5, 20]. If the stress is high enough, the mechanism of erythrocyte mechanical cell damage includes overstretching or fragmentation of the cells, hemolysis, resulting in free hemoglobin in the plasma and release of microparticles. In case of 'sublethal trauma' the red blood cells are not hemolysed yet, but their micro-rheological properties are worsening, as enhancement in aggregation and decrease in deformability [5, 25-27].

Modern investigation of hemocompatibility of various intravascular tools, as well as of various blood contacting biomaterials used in intra- or extracorporeal medical devices provided important results in the context of thrombogenicity and mechanical trauma to blood [28, 29]. In a wide range of diagnostic and therapeutic interventions the usage of various contrast materials also has an impact on fluidity of blood [30]. These issues had been widely investigated by Professor Friedrich Jung and his co-workers [29-37].

Oxygen-centered free radicals initiate chain reactions. Red blood cells can be impaired by damaging the cell membrane (lipid peroxidation) and the proteins (receptors, ion pumps, structural proteins, with the formation of sulfhydryl cross-links), as well as by alterations in the hemoglobin molecules (methemoglobin, Heinz-body formation) [4, 6, 38]. Since red blood cells are rich in iron (Fentonreaction) and un-nucleated (lack of new protein generation for repairs), they are highly sensitive to 
oxidative stress [38]. Free radicals can be generated in excessive amount during reperfusion of a previous ischemically insulted tissue and during inflammatory processes, being triggered even by the previously tissue damage [4, 39].

Nitric oxide (NO), deliberating from the endothelial cells and from erythrocytes, plays an important role in the local flow regulation, also showing a beneficial effect on red blood cell deformability. However, in the presence of superoxide anion, peroxynitrite anion is formed, which is harmful free radical that can further jeopardize the cells [39].

During acute phase reactions the hemorheological changes are non-specific: increase of plasma viscosity by elevated fibrinogen concentration and $\alpha_{2}$-macroglobulin, increase in immunoglobulin levels, decrease in albumin level, rise in leukocyte count, increase or decrease of platelet count, hemoconcentration, as well as erythrocytes' micro-rheological changes $[3,4,6]$.

The links between blood fluidity alterations and microcirculatory disturbances are complex [8, 9, $40,41]$. Impaired red blood cell deformability may contribute to an increased blood viscosity and microcirculatory deterioration [8-10, 42, 43]. Enhanced red blood cell aggregation elevates blood viscosity and increases the flow resistance $[11,12,44]$. When erythrocyte aggregation is enhanced, the axial migration of the red blood cells in the vessel becomes more expressed, resulting in a widening Poiseuille-zone that facilitates leukocyte tethering and margination, also slowing down the rolling [41, 45, 46].

Hypoxia leads to impaired endothelial cell barrier function as well [33, 47]. Additionally, altered blood rheology has an impact on the shear stress profile on the endothelial surface modulating numerous vascular functions via mechanotransducers [47, 48], thus, altered rheology can cause further progression in the pathophysiological process [4].

As clear examples for the complex hemorheological and microcirculatory changes, ischemiareperfusion and sepsis can be mentioned.

For tissue ischemia-reperfusion, in the microcirculatory bed, the "no-reflow" phenomenon is characteristic as a consequence of microvascular spasm, swelling of endothelial cells, bleb formation on the endothelial surface, increased capillary permeability, interstitial edema, micro-thrombi, neutrophil adhesion and plugging, local acidosis, and presence of red blood cells with impaired deformability and enhanced aggregation $[49,50]$. If hypovolemia also appears, arteriolar vasoconstriction develops on the basis of an increased sympathetic activation causing A1 vasoconstriction and inverse A4 vasodilation, resulting in reduction of capillary cross-sectional area and endothelial swelling [51, 52].

The pathophysiology of sepsis includes several points which link it to the rheology of blood. The microcirculatory deterioration in sepsis is multifactorial, disturbing micro-vascular blood flow and vascular resistance. Hemodynamic changes, redistribution of organ flow, vasodilatation and vasoplegia, opening arterio-venous shunt, all together determine the amount of blood entering the capillaries. In capillaries rigid blood cells may easily plugged, and as a result of endothelial dysfunction, the perfusion further decreases due to increased adhesiveness for platelets, leukocytes and erythrocytes. Furthermore, microvascular thrombosis, increased capillary permeability, edema and enhanced red blood cell aggregation also contribute to perfusion problems [53-58]. In a developed manifest sepsis red blood cell deformability worsens, fibrinogen concentration increases with resultant enhancement in red blood cell aggregation [4, 59-62]. However, in early stage, a decrease in erythrocyte aggregation might be also observed due to the fibrinogen consumption and supposed direct bacterial effects on blood cells $[62,63]$.

The initiating harmful effect and the consequent micro- and macro-rheological alterations lead to microcirculatory deterioration with decreasing perfusion. These all may cause further circulatory problems, hypoxia and tissue damage leading to further rheological disturbances [4]. The listed primary effects obviously can be associated, since hypoxia causes tissue damage, such as free radicals do [39], and as oxidative stress, for instance, may increase the sensitivity of erythrocytes to shear-mediated 
Table 1

Considerations and possible influencing factors on hemorheological results in experimental surgical models

\begin{tabular}{|c|c|c|c|c|}
\hline Experimental animal & Anesthesia, drugs & Intervention & $\begin{array}{l}\text { Blood sampling and } \\
\text { testing }\end{array}$ & $\begin{array}{l}\text { Follow-up } \\
\text { period }\end{array}$ \\
\hline $\begin{array}{l}\text { - species } \\
\text { - strain, genetic } \\
\text { background } \\
\text { - gender } \\
\text { - estrus cycle } \\
\text { - age } \\
\text { - transportation } \\
\text { - housing (including } \\
\text { microbiological } \\
\text { status) } \\
\text { - feeding } \\
\text { - comfort of animals } \\
\text { - co-morbidities }\end{array}$ & $\begin{array}{l}\text { - premedication } \\
\text { - anesthetics (type, } \\
\text { dosage) } \\
\text { - ventilation } \\
\text { - body temperature } \\
\text { maintenance } \\
\text { - intraoperative } \\
\text { volume correction } \\
\text { - anticoagulants } \\
\text { - contrast materials }\end{array}$ & $\begin{array}{l}\text { - vessel cannulation } \\
\text { - intravascular devices } \\
\text { - intubation/ } \\
\text { tracheostomy } \\
\text { - extension and } \\
\text { complexity of the } \\
\text { operation }\end{array}$ & $\begin{array}{l}\text { - sampling site } \\
\text { - anticoagulant } \\
\text { - volume } \\
\text { - repeatability } \\
\text { - sample handling } \\
\text { (storage, in vitro } \\
\text { ageing, temperature } \\
\text { possible } \\
\text { centrifugation, Htc } \\
\text { adjustment, buffers } \\
\text { method specific } \\
\text { conditions, etc) }\end{array}$ & $\begin{array}{l}\text { - postoperative } \\
\text { analgesia } \\
\text { - antibiotics } \\
\text { - wound care } \\
\text { - prevention of } \\
\text { autophagy } \\
\text { - housing } \\
\text { - feeding } \\
\text { - postoperative } \\
\text { volume } \\
\text { correction }\end{array}$ \\
\hline
\end{tabular}

damage [64] (Fig. 1). Furthermore, when the effectiveness of eliminating red blood cells with impaired deformability worsens, the rheology of circulating blood can be altered that, for instance, happens after splenectomy or in cases of hyposplenic/asplenic conditions [65].

\section{Considerations in experimental surgical models}

Following the animal protection and laboratory animal science considerations [66], well-defined and correctly designed animal experimentations are still important in biomedical research. Most of the surgical investigations, by their nature, involve animal models. Several questions exist that cannot be examined by in vitro methods or in tissue cultures.

In vivo studies have serious requirements and challenges. In Table 1 the major factors are summarized that might influence the (hemorheological) results.

Concerning the 3Rs (replacement, reduction, refinement), it is highly important to provide safe measurement methods and standardization of surgical/microsurgical skills, instruments, anesthesia, necessary sham operations as control, as well as all the circumstances of the operation. For clinical hemorheological studies a measurement technique guideline is available [13]. With respect to animal experimentation, no such guideline has been published, yet. Besides considering inter-species and gender differences $[67,68]$, sampling conditions (site, volume, repeatability, anticoagulant), sample handling (storage, preparation, centrifugation, hematocrit adjustment, usage of buffers, etc), and devicespecific sensitivity and method-related measurement conditions have to be taken into consideration when planning experiment and evaluating the results $[6,13,69]$.

\section{Conclusion}

Hemorheological parameters show alterations in surgical pathophysiological processes in a complex way. However, the changes are dominantly non-specific. Standardized experimental conditions, related to the experimental animal (species, animal welfare) anesthesia-medications, operation, sampling and, if applicable, conditions of the postoperative period, are inevitable for a safe assessment of valuable (hemorheological) results. Parallel investigations -such as microcirculatory monitoring, 
imaging techniques, other laboratory methods, histomorphology- have great importance, together with individual analysis of changes, for a better understanding of the changes and for comparability with clinical results.

\section{Acknowledgments}

Special thanks to Professor Friedrich Jung, Editor-in-Chief, who significantly contributed to the dissemination of new hemorheological findings, not only in the field of clinical hemorheology and microcirculation, but also supporting publications on basic and applied research related to many disciplines, including surgery and experimental surgery.

The authors comply with the Ethical Guidelines for Publication in Clinical Hemorheology and Microcirculation as published on the IOS Press website and in Volume 63, 2016, pp. 1-2. of this journal.

\section{References}

[1] Gelin LE. Studies in anemia of injury. Acta Chir Scand Suppl. 1956;210:1-130.

[2] Lindström BL. Lars-erik gelin in memoriam. Scand J Urol Nephrol Suppl. 1981;64:1-5.

[3] Koppensteiner R. Blood rheology in emergency medicine. Semin Thromb Hemost. 1996;22(1):89-91. doi: 10.1055/s2007-998994

[4] Baskurt OK. Mechanism of blood rheology alterations. In: Baskurt OK, Hardeman MR, Rampling MW, Meiselman HJ, editors. Handbook of Hemorheology and Hemodynamics. Amsterdam: IOS Press; 2007, pp. 170-90.

[5] Kameneva MV, Antaki JF. Mechanical trauma to blood. In: Baskurt OK, Hardeman MR, Rampling MW, Meiselman HJ, editors. Handbook of Hemorheology and Hemodynamics. Amsterdam: IOS Press; 2007, pp. $206-27$.

[6] Nemeth N, Furka I, Miko I. Hemorheological changes in ischemia-reperfusion: An overview on our experimental surgical data. Clin Hemorheol Microcirc. 2014;57(3):215-25. doi: 10.3233/CH-131648

[7] Toth Cs, Kiss F, Klarik Z, Gergely E, Toth E, Peto K, Vanyolos E, Miko I, Nemeth N. Following-up changes in red blood cell deformability and membrane stability in the presence of PTFE graft implanted into the femoral artery in a canine model. Korea-Aust Rheol J. 2014;26(2):209-15. doi: 10.1007/s13367-014-0023-3

[8] Lipowsky HH. Microvascular rheology and hemodynamics. Microcirculation. 2005;12(1):5-15. doi: 10.1080/10739680 590894966

[9] Popel AS, Johnson PC. Microcirculation and hemorheology. Annu Rev Fluid Mech. 2005;37:43-69. doi: 10.1146/annu rev.fluid.37.042604.133933

[10] Jung F, Rampling M. Role of blood viscosity in the microcirculation. Clin Hemorheol Microcirc. 2016;64(3):251-4. doi: $10.3233 / \mathrm{CH}-16810$

[11] Baskurt OK, Neu B, Meiselman, HJ. Red Blood Cell Aggregation. Boca Raton: CRC Press, 2012.

[12] Baskurt OK. In vivo correlates of altered blood rheology. Biorheology. 2008;45(6):629-38.

[13] Baskurt OK, Boynard M, Cokelet GC, Connes P, Cooke BM, Forconi S, Liao F, Hardeman MR, Jung F, Meiselman HJ, Nash G, Nemeth N, Neu B, Sandhagen B, Shin S, Thurston G, Wautier JL. International Expert Panel for Standardization of Hemorheological Methods. New guidelines for hemorheological laboratory techniques. Clin Hemorheol Microcirc. 2009;42(2):75-97. doi: 10.3233/CH-2009-1202.

[14] Reinhart WH, Chien S. Red cell rheology in stomatocyte-echinocyte transformation: Roles of cell geometry and cell shape. Blood. 1980;67:1110-8.

[15] Meiselman HJ. Morphological determinants of red cell deformability. Scand J Clin Lab Invest. 1981;(Suppl 156):27-34.

[16] Cicha I, Suzuki Y, Tateishi N, Maeda N. Changes of RBC aggregation in oxygenation-deoxygenation: PH dependency and cell morphology. Am J Physiol Heart Circ Physiol. 2003;284(6):H2335-42. doi: 10.1152/ajpheart.01030.2002

[17] Connes P, Tripette J, Mukisi-Mukaza M, Baskurt OK, Toth K, Meiselman HJ, Hue O, Antoine-Jonville S. Relationships between hemodynamic, hemorheological and metabolic responses during exercise. Biorheology. 2009;46(2):133-43. doi: 10.3233/BIR-2009-0529.

[18] Nemeth N, Miko I, Furka A, Kiss F, Furka I, Koller A, Szilasi M. Concerning the importance of changes in hemorheological parameters caused by acid-base and blood gas alterations in experimental surgical models. Clin Hemorheol Microcirc. 2012;51(1):43-50. doi: 10.3233/CH-2011-1507 
[19] Brinsfield DE, Hopf MA, Geering RB, Galletti PM. Hematological changes in long-term perfusion. J Appl Physiol. 1962;17:531-4.

[20] Leverett LB, Hellums JD, Alfrey CP, Lynch EC. Red blood cell damage by shear stress. Biophys J. 1972;12(3):257-73. doi: 10.1016/S0006-3495(72)86085-5

[21] Borthwick EM, Hill C, Rabindranath KS, Maxwell AP, McAuley DF, Blackwood B. High-volume haemofiltration for sepsis. Cochrane Database Syst Rev. 2013;1:CD008075. doi: 10.1002/14651858.CD008075

[22] Bor-Kucukatay M, Wenby RB, Meiselman HJ, Baskurt OK. Effects of nitric oxide on red blood cell deformability. Am J Physiol Heart Circ Physiol. 2003;284(5):H1577-84. doi: 10.1152/ajpheart.00665.2002

[23] Ulker P, Sati L, Celik-Ozenci C, Meiselman HJ, Baskurt OK. Mechanical stimulation of nitric oxide synthesizing mechanisms in erythrocytes. Biorheology. 2009;46(2):121-32. doi: 10.3233/BIR-2009-0532

[24] Meram E, Yilmaz BD, Bas C, Atac N, Yalcin O, Meiselman HJ, Baskurt OK. Shear stress-induced improvement of red blood cell deformability. Biorheology. 2013;50(3-4):165-76. doi: 10.3233/BIR-130637

[25] Horobin JT, Sabapathy S, Simmonds MJ. Repetitive supra-physiological shear stress impairs red blood cell deformability and induces hemolysis. Artif Organs. 2017;41(11):1017-25. doi: 10.1111/aor.12890

[26] Simmonds MJ, Atac N, Baskurt OK, Meiselman HJ, Yalcin O. Erythrocyte deformability responses to intermittent and continuous subhemolytic shear stress. Biorheology. 2014;51(2-3):171-85. doi: 10.3233/BIR-140665

[27] Simmonds MJ, Meiselman HJ. Prediction of the level and duration of shear stress exposure that induces subhemolytic damage to erythrocytes. Biorheology. 2016;53(5-6):237-49. doi: 10.3233/BIR-16120

[28] Jansen P, van Oeveren W, Capel A, Carpentier A. In vitro haemocompatibility of a novel bioprosthetic total artificial heart. Eur J Cardiothorac Surg. 2012;41(6):e166-72. doi: 10.1093/ejcts/ezs187

[29] Jung F, Braune S. Thrombogenicity and hemocompatibility of biomaterials. Biointerphases. 2015;11(2):029601. doi: $10.1116 / 1.4938557$

[30] Jung F, Mrowietz C, Gerk U, Franke RP. Influence of a radiographic contrast media (Iopentol) with different viscosities on capillary perfusion in patients with coronary artery disease. Clin Hemorheol Microcirc. 2013;53(1-2):201-8. doi: 10.3233/CH-2012-1557

[31] Franke RP, Fuhrmann R, Hiebl B, Jung F. Influence of various radiographic contrast media on the buckling of endothelial cells. Microvasc Res. 2008;76(2):110-3. doi: 10.1016/j.mvr.2008.05.002

[32] Franke RP, Krüger A, Scharnweber T, Wenzel F, Jung F. Effects of radiographic contrast media on the micromorphology of the junctional complex of erythrocytes visualized by immunocytology. Int J Mol Sci. 2014;15(9):16134-52. doi: 10.3390/ijms 150916134

[33] Jung C, Jung F, Kelm M. The microcirculation in hypoxia: The center of the battlefield for oxygen. Clin Hemorheol Microcirc. 2016;63(3):169-72. doi: 10.3233/CH-1663301

[34] Jung F, Wischke C, Lendlein A. Degradable, multifunctional cardiovascular implants: Challenges and hurdles. MRS Bull. 2010;35(8):607-13. doi: 10.1557/mrs2010.529

[35] Klopfleisch R, Jung F. The pathology of the foreign body reaction against biomaterials. J Biomed Mater Res A. 2017;105(3):927-40. doi: 10.1002/jbm.a.35958

[36] Neffe AT, von Ruesten-Lange M, Braune S, Luetzow K, Roch T, Richau K, Jung F, Lendlein A. Poly(ethylene glycol) grafting to poly(ether imide) membranes: Influence on protein adsorption and thrombocyte adhesion. Macromol Biosci. 2013;13(12):1720-9. doi: 10.1002/mabi.201300309

[37] Reviakine I, Jung F, Braune S, Brash JL, Latour R, Gorbet M, van Oeveren W. Stirred, shaken, or stagnant: What goes on at the blood-biomaterial interface. Blood Rev. 2017;31(1):11-21. doi: 10.1016/j.blre.2016.07.003

[38] Baskurt OK, Temiz A, Meiselman HJ. Effect of superoxide anions on red blood cell rheologic properties. Free Radic Biol Med. 1998;24(1):102-10.

[39] Eltzschig H, Eckle T. Ischemia and reperfusion - from mechanism to translation. Nat Med. 2011;17(11):1391-1401. doi: $10.1038 / \mathrm{nm} .2507$

[40] Nemeth N, Kiss F, Klarik Z, Toth E, Mester A, Furka I, Miko I. Simultaneous investigation of hemodynamic, microcirculatory and arterio-venous micro-rheological parameters in infrarenal or suprarenal aortic cross-clamping model in the rat. Clin Hemorheol Microcirc. 2014;57(4):339-53. doi: 10.3233/CH-131724

[41] Reinhart WH, Piety NZ, Shevkoplyas SS. Influence of feeding hematocrit and perfusion pressure on hematocrit reduction (Fåhraeus effect) in an artificial microvascular network. Microcirculation. 2017;24(8). doi: 10.1111/micc.12396

[42] Chien S, Usami S, Dellenback RJ, Gregersen MI. Blood viscosity: Influence of erythrocyte deformation. Science. 1967;157(3790):827-9.

[43] Nemeth N, Szabo A. Microcirculation. In: Huifang C, Martins P, editors. Advances in Experimental Surgery: Volume 2. Hauppauge, New York: Nova Science Publishers; 2017;41. in press (ISBN:978-1-53612-773-7).

[44] Chien S, Usami S, Dellenback RJ, Gregersen MI, Nanninga LB, Guest MM. Blood viscosity: Influence of erythrocyte aggregation. Science. 1967;157(3790):829-31. 
[45] Katanov D, Gompper G, Fedosov DA. Microvascular blood flow resistance: Role of red blood cell migration and dispersion. Microvasc Res. 2015;99:57-66. doi: 10.1016/j.mvr.2015.02.006

[46] Yalcin O, Wang Q, Johnson PC, Palmer AF, Cabrales P. Plasma expander viscosity effects on red cell-free layer thickness after moderate hemodilution. Biorheology. 2011;48(5):277-91. doi: 10.3233/BIR-2012-0598

[47] Gori T, Forconi S. Endothelium and hemorheology. In: Baskurt OK, Hardeman MR, Rampling MW, Meiselman HJ, editors. Handbook of Hemorheology and Hemodynamics. Amsterdam: IOS Press; 2007, pp. 339-50.

[48] Chandran KB, Rittgers SE, Yoganathan AP. Rheology of blood and vascular mechanics. In: Chandran KB, Rittgers SE, Yoganathan AP, editors. Biofluid Mechanics. Boca Raton: CRC Press, 2012, pp. 109-54.

[49] Reffelmann T, Kloner RA. The "no-reflow" phenomenon, basic science and clinical correlates. Heart. 2002;87(2):162-8.

[50] Vollmar B, Menger MD. Intestinal ischemia/reperfusion: Microcirculatory pathology and functional consequences. Langenbecks Arch Surg. 2011;396(1):13-29. doi: 10.1007/s00423-010-0727-x

[51] Mazzoni MC, Intaglietta M, Cragoe EJ Jr, Arfors KE. Amiloride-sensitive Na+ pathways in capillary endothelial cell swelling during hemorrhagic shock. J Appl Physiol. 1992;73(4):1467-73.

[52] Szopinski J, Kusza K, Semionow M. Microcirculatory responses to hypovolemic shock. J Trauma. 2011;71(6):1779-88. doi: 10.1097/TA.0b013e31823a05b5

[53] Spronk PE, Zandstra DF, Ince C. Bench-to-bedside review: Sepsis is a disease of the microcirculation. Crit Care. 2004;8(6):462-8. doi: 10.1186/cc2894

[54] Ince C. The microcirculation is the motor of sepsis. Crit Care. 2005;9(Suppl 4):S13-9. doi: 10.1186/cc3753

[55] Remick DG. Pathophysiology of sepsis. Am J Pathol. 2007;170(5):1435-44. doi: 10.2353/ajpath.2007.060872

[56] Trzeciak S, Dellinger RP, Parrillo JE, Guglielmi M, Bajaj J, Abate NL, Arnold RC, Colilla S, Zanotti S, Hollenberg SM. Microcirculatory Alterations in Resuscitation and Shock Investigators. Early microcirculatory perfusion derangements in patients with severe sepsis and septic shock: Relationship to hemodynamics, oxygen transport, and survival. Ann Emerg Med. 2007;49(1):88-98. 98.e1-2. doi: 10.1016/j.annemergmed.2006.08.021

[57] Lundy DJ, Trzeciak S. Microcirculatory dysfunction in sepsis. Crit Care Clin. 2009;25(4):721-31. doi: 10.1016/j.ccc.2009.06.002

[58] Ostergaard L, Granfeldt A, Secher N, Tietze A, Iversen NK, Jensen MS, Andersen KK, Nagenthiraja K, GutiérrezLizardi P, Mouridsen K, Jespersen SN, Tonnesen EK. Microcirculatory dysfunction and tissue oxygenation in critical illness. Acta Anaesthesiol Scand. 2015;59(10):1246-59. doi: 10.1111/aas.12581

[59] Baskurt OK, Temiz A, Meiselman HJ. Red blood cell aggregation in experimental sepsis. J Lab Clin Med. 1997;130(2):183-90.

[60] Reggiori G, Occhipinti G, De Gasperi A, Vincent JL, Piagnerelli M. Early alterations of red blood cell rheology in critically ill patients. Crit Care Med. 2009;37(12):3041-6. doi: 10.1097/CCM.0b013e3181b02b3f

[61] Donadello K, Piagnerelli M, Reggiori G, Gottin L, Scolletta S, Occhipinti G, Zouaoui Boudjeltia K, Vincent JL. Reduced red blood cell deformability over time is associated with a poor outcome in septic patients. Microvasc Res. 2015;101:8-14. doi: 10.1016/j.mvr.2015.05.001

[62] Bateman RM, Sharpe MD, Singer M, Ellis CG. The effect of sepsis on the erythrocyte. Int J Mol Sci. 2017;18(9):pii: E1932. doi: 10.3390/ijms18091932

[63] Nemeth N, Fulesdi B. Concerning hemorheological disturbances in sepsis. De omnibus dubitandum est. Series on Biomechanics. 2016;30(1):20-6.

[64] McNamee AP, Horobin JT, Tansley GD, Simmonds MJ. Oxidative stress increases erythrocyte sensitivity to shearmediated damage. Artif Organs. 2017. doi: 10.1111/aor.12997. [Epub ahead of print]

[65] Miko I, Nemeth N, Sogor V, Kiss F, Toth E, Peto K, Furka A, Vanyolos E, Toth L, Varga J, Szigeti K, Benkő I, Olah AV, Furka I. Comparative erythrocyte deformability investigations by filtrometry, slit-flow and rotational ektacytometry in a long-term follow-up animal study on splenectomy and different spleen preserving operative techniques: Partial or subtotal spleen resection and spleen autotransplantation. Clin Hemorheol Microcirc. 2017;66(1):83-96. doi: $10.3233 / \mathrm{CH}-160231$

[66] van Zutphen LFM, Baumans V, Beynen AC, editors. Principles of Laboratory Animal Science. Amsterdam: Elsevier; 2001.

[67] Chien S, Usami S, Dellenback RJ, Bryant CA. Comparative hemorheology-hematological implications of species differences in blood viscosity. Biorheology. 1971;8(1):35-57.

[68] Windberger U, Baskurt OK. Comparative hemorheology. In: Baskurt OK, Hardeman MR, Rampling MW, Meiselman HJ, editors. Handbook of Hemorheology and Hemodynamics. Amsterdam: IOS Press; 2007, pp. 267-85.

[69] Hardeman MR, Goedhart PT, Shin S. Methods in hemorheology. In: Baskurt OK, Hardeman MR, Rampling MW, Meiselman HJ, editors. Handbook of Hemorheology and Hemodynamics. Amsterdam: IOS Press; 2007, pp. 242-66. 